\title{
Effects of Competition on The Crown Width Allometry for Dominant Trees on Good Sites of Vegetative Clonal Teak (Tectona grandis Linn. f.) in Java, Indonesia
}

\author{
Ronggo Sadono \\ Department of Forest Management, Faculty of Forestry, Universitas Gadjah Mada, \\ Jl. Agro No 1, Bulaksumur, Yogyakarta, Indonesia 55281
}

Received June 27, 2019/Accepted August 5, 2019

\begin{abstract}
The vegetative clonal teak is fast-growing, exhibits relatively uniform growth, and is sensitive to crown competition. The crown width dimension correlates positively with the size of the diameter ( $C W$ allometry). We investigated the effects of competition on $C W$ allometry for dominant trees on good sites and the prediction accuracy of $C W$ allometry. The data were measured during 2015-2017. The Hegyi index with a fixed $30^{\circ}$ search cone method was used to measure competition. The scatter plot of all observations was used to identify the general pattern of CW over diameter, and competition index with both diameter and $C W$. The data were classified into three groups, ignored, free, and occurred competition data sets. Moreover, the occurred competition data set was categorized into three levels: low, medium, and heavy. The power model was used for parameterization of CW allometry. The dispersion of $C W$ over diameter for all observations exhibited a moderate positive correlation, as well as the competition index with both diameter and $C W$. For the ignored-competition data set, the CW allometry was able to describe approximately $37.2 \%$ of observed CW. Interestingly, however, the prediction accuracy increased to $44.6 \%$ for the free competition data set. In contrast, the capability of the CW allometry for the occurred competition data set declined sharply to $9.1 \%$. Among the occurred competition data sets, the heavier the subject trees competed, the lower the $C W$ allometry explained the variations. However, the CW allometry was completely not able to describe the observed $C W$ in the heavy competition level.
\end{abstract}

Keywords: competition measure, crown width, distance-dependent competition index, fixed $30^{\circ}$ search cone, radii measurement.

*Correspondence author, email: rsadono@ugm.ac.id, ph: +62-274-548815,fax: +62 -274-548815

\section{Introduction}

The recently improved vegetative clonal teak (Tectona grandis Linn. f.) in Java are fast-growing, exhibit relatively uniform growth, and are shade-intolerant and sensitive to crown competition. The tree crown exhibits a lateral development in a plantation forest, which plays an important role in determining the required growing space. Previous studies have shown that crown radius $(\mathrm{CR})$ and, by extension, crown width $(\mathrm{CW})$ correlate with the growing space requirements for trees to grow in a plantation (Dalhausen et al., 2016; Rahmadwiati et al., 2016; Sadono, 2018). Moreover, these variables are useful to estimate the required growing space and the number of potential final crop trees according to a given species (Zuhaidi, 2013; Pretzsch et al., 2015; Raptis et al., 2018). Therefore, CW is an important variable for projecting the future growing space requirement for existing trees of a certain age (Dahlhausen et al., 2016). Conversely, the available growing space limits the crown size. Furthermore, in an even-aged plantation forest consisting of shade-intolerant species, such as teak, CW regulates the optimal number of stems per hectare, or the stand density (Sadono, 2018).

$\mathrm{CW}$ is calculated from a direct measurement of CR components. This measurement is expensive and timeconsuming (Fu et al., 2013; Sharma et al., 2016; Yang \& Huang, 2017), especially under dense conditions where the crown periphery is not clearly visible. To obtain necessary $\mathrm{CW}$ data without the difficulty of indirect measurement, $\mathrm{CW}$ must be modeled as a function of other tree characteristics. These models require a large number of samples for developing an accurate prediction of CW (Lei et al., 2018). Studies conducted by Zuhaidi (2013) and Ibrahim and Osman (2014) have demonstrated that the change in CW size is related to its diameter. Hereafter, this relationship is termed as $\mathrm{CW}$ allometry. The advantage of using allometric relationships rather than other equation types is their strong foundation in biological realism (Dahlhausen et al., 2016). Moreover, the development of $\mathrm{CW}$ allometry has continuously remained as a focus of research interest, and it is also useful for estimating wood volume and also for integration with remote sensing analysis in the frame of sustainable forests (Raptis et al., 2018). 
CW can be modeled as a function of diameter alone (Huxley \& Teissier, 1936) using simple ordinary least squares regression for parameter estimation (Zuhaidi, 2013; Ibrahim \& Osman, 2014). Diameter at breast height correlates with crown width for several species and stand types and is often used as an essential and effective predictor of crown width (Yang \& Huang, 2017; Raptis et al., 2018). However, this model is unsuitable for larger spatial scales because CW allometry is strongly influenced by site quality, stand density, and other factors that vary spatially and temporally (Fu et al., 2017; Lei et al., 2018). Therefore, to model CW effectively, other factors such as dominant height and site quality must be considered (Fu et al., 2013; Hao et al., 2015). For example, Sharma et al. (2016) included the mean height of dominant trees as a proxy for site quality as a predictor variable in their model of $\mathrm{CW}$.

Because $\mathrm{CW}$ is significantly influenced by competition from neighbors, the effects of competition must also be considered for a comprehensive crown model (Thorpe et al., 2010). In addition, Pretzsch et al. (2015) recommended that a competition situation must be taken into consideration in the $\mathrm{CW}$ allometry as the growth of both crown size and stem diameter is highly sensitive to competition. The inclusion of competition measure has been investigated by Sharma et al. (2016) and Lei et al. (2018), and their results demonstrated that spatially explicit competition measure had a significant influence on the CW model. It was then assumed that the proposed competition measure could provide adequate number of data from the field for the purpose of $\mathrm{CW}$ allometry. In addition, it has been hypothesized that the occurrence of competition affected the prediction accuracy of CW allometry. Accordingly, this study was conducted to investigate the effects of spatially explicit competition on
$\mathrm{CW}$ allometry. An accurate and applicable prediction of $\mathrm{CW}$ would assist managers to determine a thinning strategy for these superior teak plantations to their optimal stand density. Meanwhile, an appropriate thinning strategy is urgently awaited to retain the expected growth of this plantation.

\section{Methods}

Study area This study was conducted in the forest management units (FMUs) of Madiun, Ngawi, and Saradan. These three FMUs belong to a nationally owned forest enterprise, Perum Perhutani, and are located in the western province of East Java. The geographical coordinates range from $7^{\circ} 14^{\prime} 40^{\prime \prime}$ to $7^{\circ} 58^{\prime} 12^{\prime \prime} \mathrm{S}$ latitude and $111^{\circ} 7^{\prime} 29^{\prime \prime}$ to $111^{\circ} 49^{\prime} 58^{\prime \prime}$ E longitude (Figure 1).

The altitude ranges from 0 to 661,0 to 160 , and 49 to 617 masl for Madiun, Ngawi, and Saradan, respectively. The average annual precipitation has been recorded at $1660 \mathrm{~mm}$ in both Madiun and Saradan, whereas it was $2034 \mathrm{~mm}$ in Ngawi. The mean annual temperature ranged from $23.0^{\circ} \mathrm{C}$ to $32.5^{\circ} \mathrm{C}, 27.0^{\circ} \mathrm{C}$ to $32.0^{\circ} \mathrm{C}$, and $22.0^{\circ} \mathrm{C}$ to $32.0^{\circ} \mathrm{C}$ for Madiun, Ngawi, and Saradan, respectively. Soil structure of the three FMUs are relatively similar as follows: sand, loam, and sandy loam. As with soil structure, soil texture of the three FMUs are also relatively similar as follows: slightly clay, clay, and crumb.

Sampling and plot design In this study, vegetative teak clones from shoot cuttings were used, which were planted in 2009 using a $3 \times 3 \mathrm{~m}$ initial planting arrangement. Perum Perhutani has been planting these teak trees and has improved the clones using the taungya management system, in which local communities may grow certain crops in the early 2 years of plantation. Intermediate cutting has never



Figure 1 The study area is located primarily in the western part of the province of East Java, Indonesia. 
been conducted until the clones reach the age of 8 years. Theoretically, teak stands with a stock of more than 1000 trees $\mathrm{ha}^{-1}$, then pre-commercial thinning must be applied by as early as 5 years (Pachas et al., 2019).

Vegetative teak clones are considered as fast-growing and exhibit relatively uniform stands. At the age of 3 years, the tree crown is obvious and measurable. This reseach was conducted in the 3 years of good growing sites. Fu et al. (2013) and Hao et al. (2015) reported that the site quality class influenced the crown dimension and ultimately affected the CW diameter model. The use of these compartments showing good growth was intended as a proxy for good site quality class due to the unavailability of the site index for the vegetative clonal teak plantation at the study site. However, due to the lack of such a site index, dominant height has been used as a proxy (Sharma et al., 2016).

In the stand with more than three years of age, several good compartments were selected purposively in each stand age and in each forest management unit, and in each year of measurement. However, this selection procedure was directed to obtain either for model data and validation data purpose in the final year of measurement. In addition, in each selected good compartment, 30 temporary plots were established, which will hereafter be termed as a plot, purposively according to the position of the dominant tree in the center of the plot. The dominant tree was in good health and identified based on visual appearance in terms of height, diameter, and quality. Simplifying indicators, the dominant tree is taller in terms of tree height and larger in terms of stem diameter than the surrounding trees. The good quality was characterized as having a straight and cylindrical stem, the highest clear bole, and as much of a cylindrical crown as possible. Dominant trees became the focus of the study, because such trees perform larger increases in light use and light use efficiency in comparison to other trees. In addition, these trees play a significant contribution to stand productivity (Campoe et al., 2013).

The plot is a square and follows the spacing scheme of $3 \times$ $3 \mathrm{~m}$. The sampled tree was the dominant tree surrounded by eight possible neighboring trees. The neighboring trees were numbered clockwise starting from the northwest. The distance of neighboring trees to the sampled tree was $3 \mathrm{~m}$ and $4.24 \mathrm{~m}$ for even and odd neighbors, respectively.

Plot measurement $\mathrm{CW}$ is obtained from the measurement of the crown radii $(r)$ either in the four subcardinal directions (Fu et al., 2013; Zuhaidi, 2013; Hao et al., 2015; Sadono, 2016; Sharma et al., 2016; Fu et al., 2017; Sharma et al., 2017; Lei et al., 2018; Sadono, 2018) or in more detail in the eight subcardinal directions (Ibrahim \& Osman, 2014; Pretzsch, 2015). Two methods have been frequently applied to measure $r$, i.e., the projection method, as horizontal distances from the center of the trunk to the greatest extent of the projected edge of the crown (Fu et al., 2013; Zuhaidi, 2013; Goodman et al., 2014; Ibrahim and Osman, 2014; Sadono, 2016; Sharma et al., 2016; Fu et al., 2017; Sharma et al., 2017; Lei et al., 2018; Sadono, 2018), and the vertical sighting method that is rather inaccurate compared with the projection method (Pretzsch et al., 2015).

The CR was then computed using either the ordinary arithmetic mean of $\mathrm{r}$ or the quadratic mean of $r$ (Russel \& Weiskittel, 2011; Pretzsch et al., 2015; Sadono, 2018). The $\mathrm{CW}$ value was obtained first by either doubling the value of $\mathrm{CR}$ from the quadratic mean of $r$ in the four subcardinal directions (Russel \& Weiskittel, 2011; Sadono, 2018) or second by directly summing up $r$ in the four radii and dividing by two (Fu et al., 2013; Hao et al., 2015; Sharma et al., 2016; Fu et al., 2017; Lei et al., 2018).

Over-bark diameter at breast height (D) was measured for the sampled tree and all existing neighboring trees within each sampled plot using a diameter tape to the nearest $0.1 \mathrm{~m}$. Total tree height was measured for all existing neighboring trees within each sampled plot using a Haga altimeter to the nearest $1 \mathrm{~m}$. For every sampled tree in each plot, four $r$ values in the cardinal directions $\left(r_{\mathrm{N}}, r_{\mathrm{E}}, r_{\mathrm{S}}\right.$, and $\left.r_{\mathrm{W}}\right)$ were measured using a fiberglass measuring tape to the nearest $0.1 \mathrm{~m}$ based on the projection method. CR was obtained from the quadratic mean of the four $r$ values, and $\mathrm{CW}$ was eventually doubled from CR.

Data collection for the model fitting was conducted for the first time in 2015 for 64 selected compartments with 1920 plots comprising stands aged 3-6 years. In the second year, we measured an additional 1380 plots in 46 selected compartments comprising stands aged 3-7 years. In 2017, we continued the measurement for another 1140 plots in 38 selected compartments consisting of stands of 3-8 years of age. In this year, we also conducted data collection for the purpose of model validation with another 1080 plots in 36 selected compartments comprising stands aged 3-8 years. Therefore, a total of 5520 different plots were measured during this period consisting of 4440 and 1080 plots for model fitting and model validation, respectively.

Competition measure The procedure for competition calculation starts with the determination of the competitor trees, i.e., the neighboring trees whose height exceeds the critical virtual height. This virtual height is calculated based on the distance of the neighboring trees and the search cone with a determined opening angle (Burkart \& Tomé, 2012; Sadono, 2014). In this case, the opening angle was determined as $30^{\circ}$ developed from a previous study (Sadono, 2014) and termed as fixed $30^{\circ}$ search cone method 9 (Figure 2). In addition, competition measure was computed using a distance-dependent or a spatially explicit approach. This distance-dependent competition index (CI) was slightly better (Yang \& Huang, 2017) and exhibited a higher correlation with growth than the distance-independent competition measure (Tenzin et al., 2017).

Furthermore, several studies have shown that the most frequent distance-dependent CI for the subject trees, focussed trees for competition calculation was obtained according to the Hegyi index (1974) (Thorpe et al., 2010; Sadono, 2014; Sharma et al., 2016; Sharma et al., 2017; Yang \& Huang, 2017; Tenzin et al., 2017; Lei et al., 2018; Höwler et al., 2019). This approach follows the principle that larger and closer competitors would exert a higher competition effect on a subject tree (Tenzin et al., 2017; Lei et al., 2018). The results of the CI calculation for both fitting and validation data were categorized according to $\mathrm{CI}$ values into two groups, $\mathrm{CI}=0.0$ (no competition occurred) and $\mathrm{CI}>0.0$ 
(competition occurred) for free competition data set and competition data set, respectively. The competition data set was then classified into three levels based on the CI values, $0.1-1.0,1.1-2.0$, and $>2.0$ for light, medium, and heavy competition, respectively.

\section{Data analysis}

1 Graphical presentation. The scatter plot of all observations was used to identify the general pattern of $\mathrm{CW}$ over diameter. This technique was also used to determine the relationship between CI and both diameter and $\mathrm{CW}$. The Pearson correlation $r$ value was used to indicate the strength and the direction of those three pairs of relationship. Three levels were applied for indicating strength, low, moderate, and strong, with Pearson $r$ values of $<0.34,0.34-0.66$, and $>0.66$, respectively.

2 Model Fitting. The overall $\mathrm{CW}$ for the fitting data irrespective of the competition was predicted using diameter by SPSS version 22. The power model was used for parameterization. CW allometry was evaluated for the prediction accuracy using the following three statistical criteria: (1) the coefficient of determination $\left(r^{2}\right)$, which indicates the portion of the total variance explained by CW allometry, (2) the standard error of the estimate (SEE), which demonstrates the precision of the estimates, and (3) the graph of the residuals, which ensures the fulfillment of assumption that variances are equal for all values of the predictor. A statistical significance of 0.05 was applied in all statistical analyses.

3 Model validation. Normalized root mean square error (NRMSE) and mean bias error (MBE) were used to

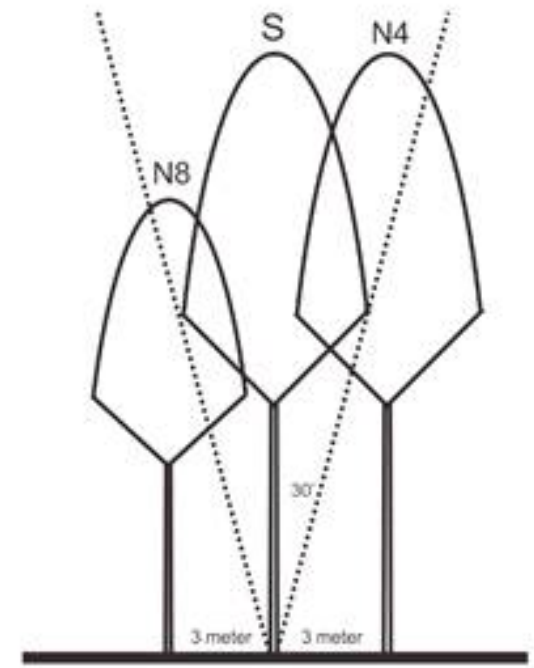

Figure 2 Illustration of the fixed $30^{\circ}$ search cone method. The angle between two symetrical dashed lines is $30^{\circ}$. S is the subject tree (the focus of the competition calculation), $\mathrm{N} 4$ and $\mathrm{N} 8$ are neighbor trees with a distance of 3 meters from S. The height of both $\mathrm{N} 4$ and $\mathrm{N} 8$ cross the dashed line, therefore both $\mathrm{N} 4$ and N8 are competitors of S. evaluate the feasibility of CW allometry. The NRMSE provides a measure of the relative differences (0-100\%) between the predicted values by $\mathrm{CW}$ allometry and the observed values from validation data. CW allometry is considered to be excellent when NRMSE is $<10 \%$, good when NRMSE is 10-20\%, fair when NRMSE is 20-30\%, and poor when NRMSE is $>30 \%$ (Fayed et al. 2015; Hayashi et al. 2018). On the other hand, the MBE value is the difference between the mean of the CW allometry values and the validation data. It can be used to identify whether the $\mathrm{CW}$ allometry overestimates $(\mathrm{MBE}>0)$ or underestimates $(\mathrm{MBE}<0)$ the validation data ( $\mathrm{Li}$ et al., 2015; He et al., 2018).

4 Effects of competition. The same method was conducted for both the free competition data set and the competition data set. Both results were compared to identify the effect of competition on the quality of $\mathrm{CW}$ allometry. This comparison was made to investigate the results of several previous studies that stated that competition affected the tree CW model (Sharma et al., 2016; Lei et al., 2018). Finally, to clarify the effects of the level of CI on the CW allometry, the fitting model was used on the competition data set that has been classified into light, medium, and heavy competition levels.

\section{Results and Discussion}

General pattern of CW over diameter Based on a total of 5520 sampled dominant trees, the $\mathrm{CW}$ exhibited a clear general pattern over diameter, where the larger the size of the diameter, the greater the dimension of CW (Figure 3). The correlation analysis between the two variables showed a positive correlation, with the Pearson $r$ value being approximately $0.58(p<0.000)$ or at a moderate level. This pattern conformed for further investigation of $\mathrm{CW}$ allometry.

In addition, the size of the diameter showed a positive correlation with the CI (Figure 4a). The Pearson $r$ value for these two variables was approximately $0.62(p<0.000)$ or at a moderate level. Moreover, the dimension of $\mathrm{CW}$ also demonstrated a positive correlation with the CI (Figure 4b). However, the Pearson $r$ value was approximately 0.38 $(p<0.000)$ or still at a moderate level. Both diameter and CW data indicated greater dispersion at zero CI or free competition than the other CI. Therefore, a separate level of competition was taken into account for further investigation.

A total of 5520 sampled dominant trees were classified into 4440 and 1080 for model fitting and model validation, respectively. This amounted to 4440 fitting data that covered $\mathrm{D}$ values from 6.2 to $28.0 \mathrm{~cm}$. Subsequently, the $\mathrm{CW}$ varied between 0.82 and $6.85 \mathrm{~m}$, and the CI values ranged from free (0.0) to the heaviest with 2.83. On the other hand, the total of 1080 validation data covered D values from 7.5 to $26.7 \mathrm{~cm}$. Later, the CW varied between 0.83 and $6.51 \mathrm{~m}$, and the CI values ranged from free $(0.0)$ to the heaviest with 2.50 . In addition, the number of fitting data consisted of 1331 observations or approximately $30 \%$ of free competition data set and most of the others (3109 observations) that belonged to the competition data set.

Among these, $70 \%$ of competition data sets were classified according to the level of CI values with the following proportions: $44.5 \%, 51 \%$, and $2.5 \%$ for light, 
Table 1 Model equation and model description as well as model code for investigating the effects of competition on CW allometry

\begin{tabular}{|c|c|c|}
\hline $\begin{array}{l}\text { Model equation } \\
\text { (Huxley \& } \\
\text { Teissier, 1936; } \\
\text { Sharma et al., 2016) } \\
\end{array}$ & Model description & Model code \\
\hline $\mathrm{CW}=\mathrm{b}_{0} * \mathrm{D}^{\mathrm{b} 1}$ & $\begin{array}{l}\text { Predicting crown width using diameter, covering all observations irrespective } \\
\text { of the occurrence of competition }\end{array}$ & $\mathrm{M}$ \\
\hline $\mathrm{CW}_{\mathrm{f}}=\mathrm{b}_{0} * \mathrm{D}_{\mathrm{f}}^{\mathrm{b} 1}$ & $\begin{array}{l}\text { Predicting crown width using diameter within all observations with no } \\
\text { occurrence of competition }\end{array}$ & $\mathrm{M}_{\mathrm{f}}$ \\
\hline $\mathrm{CW}_{\mathrm{c}}=\mathrm{b}_{0} * \mathrm{D}_{\mathrm{c}}^{\mathrm{b} 1}$ & $\begin{array}{l}\text { Predicting crown width using diameter within all observations with } \\
\text { occurrence of competition }\end{array}$ & $\mathrm{M}_{\mathrm{c}}$ \\
\hline $\mathrm{CW}_{\mathrm{lc}}=\mathrm{b}_{0} * \mathrm{D}_{\mathrm{lc}}{ }^{\mathrm{bl}}$ & $\begin{array}{l}\text { Predicting crown width using diameter within light competition level, with } \\
\text { competition index between } 0.1 \text { and } 1.0\end{array}$ & $\mathrm{M}_{\mathrm{lc}}$ \\
\hline $\mathrm{CW}_{\mathrm{mc}}=\mathrm{b}_{0} * \mathrm{D}_{\mathrm{mc}}^{\mathrm{b} 1}$ & $\begin{array}{l}\text { Predicting crown width using diameter within medium competition level, with } \\
\text { competition index between } 1.1 \text { and } 2.0\end{array}$ & $\mathrm{M}_{\mathrm{mc}}$ \\
\hline $\mathrm{CW}_{\mathrm{hc}}=\mathrm{b}_{0} * \mathrm{D}_{\mathrm{hc}}{ }^{\mathrm{b} 1}$ & $\begin{array}{l}\text { Predicting crown width using diameter within heavy competition level, with } \\
\text { competition index }>2.0\end{array}$ & $\mathrm{M}_{\mathrm{hc}}$ \\
\hline
\end{tabular}

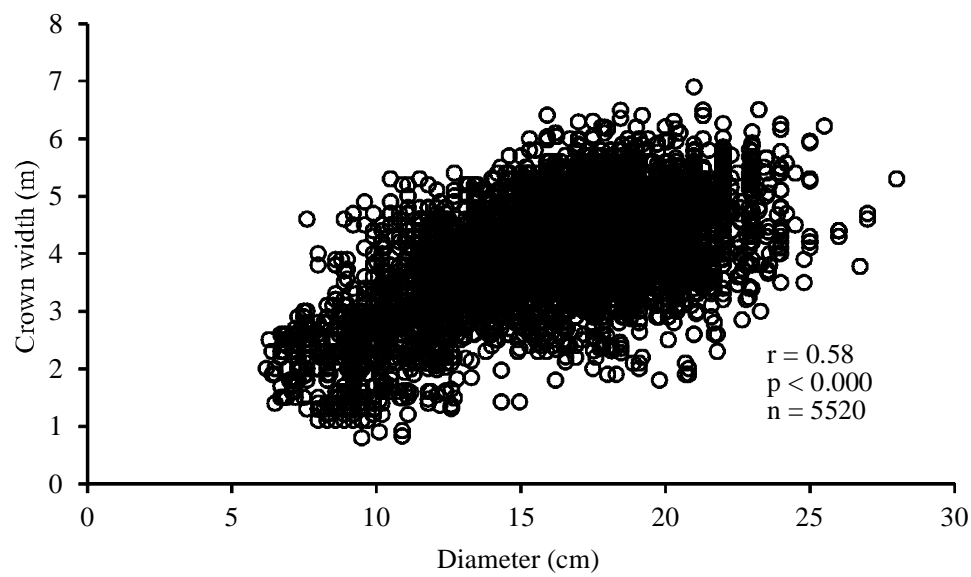

Figure 3 Scatter plot demonstrating the pattern between crown width dimension $(\mathrm{m})$ and the size of diameter $(\mathrm{cm})$ for all sampled dominant trees.

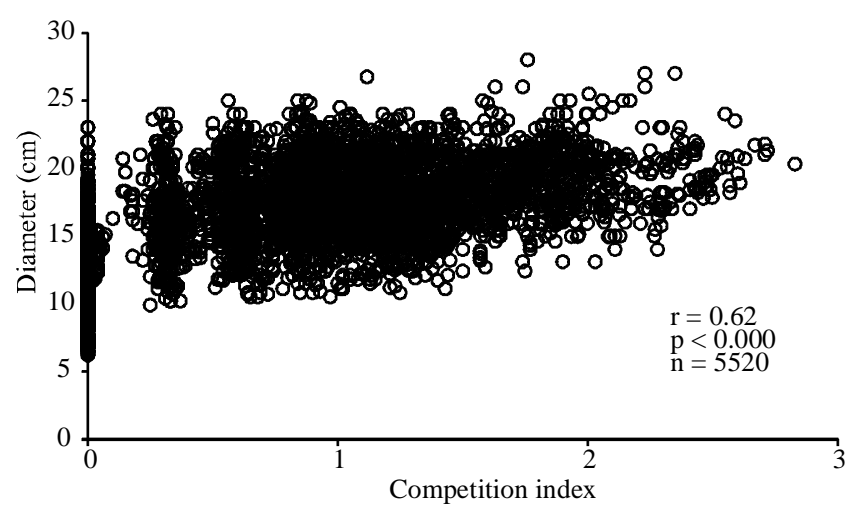

(a)

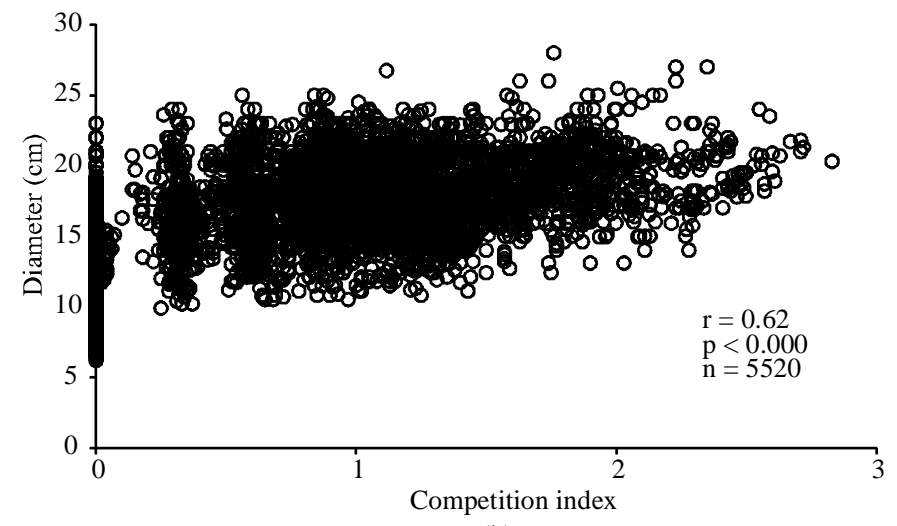

(b)

Figure 4 Scatter plot displaying the correlation between (a) diameter $(\mathrm{cm})$ and $(\mathrm{b})$ crown width $(\mathrm{m})$ and competition index. 
medium, and heavy competition, respectively. On the other hand, the composition of validation data consisted of 219 observations or approximately $20 \%$ of free competition data set and most of the others $(80 \%)$ that belonged to the competition data set (Table 2).

CW allometry for model fitting data Application of the CW allometry to all data was achieved using the following equation: $\mathrm{CW}=0.657 * \mathrm{D}^{0.644}$. This $\mathrm{CW}$ allometry was able to explain CW variations by approximately $37.2 \%$. The SSE amounted to $0.210 \mathrm{~m}$ (Figure 5a). The CW allometry, as well as all parameters, was statistically significant.

Visual observation of the graph of residuals showed that there was no obvious pattern (Figure 5b). This clearly indicated that there were no identified heteroscedasticity symptoms. In other words, the CW allometry fulfilled the homoscedasticity requirement. The residuals dispersed mostly within -2 to $2 \mathrm{~m}$, and the predicted values of $\mathrm{CW}$ ranged within 2.0-5.5 m. Most of the residuals were clustered in the surrounding 0 value with a predicted value of $4 \mathrm{~m}$.

Evaluation of the obtained $\mathrm{CW}$ allometry with the validation data indicated that the denoted $\mathrm{CW}$ was surprisingly balanced between the upper and lower estimations with an MBE value of $0.002 \mathrm{~m}$ (Figure $5 \mathrm{c}$ ). Moreover, the CW allometry was categorized at good level with $19.2 \%$ based on the NRMSE criterion.

CW allometry for free competition data set Application of the $\mathrm{CW}$ allometry for the free competition data set was achieved using the following equation: $\mathrm{CW}_{\mathrm{f}}=0.318 * \mathrm{D}_{\mathrm{f}}^{0.938}$. This CW allometry was able to explain $\mathrm{CW}$ variations by approximately $44.6 \%$. The SSE amounted to $0.249 \mathrm{~m}$ (Figure 6a). The CW allometry, as well as all parameters, was statistically significant.
Visual analysis of the graph of residuals displayed no obvious pattern (Figure $6 \mathrm{~b}$ ). This was a clear indication that there were no identified heteroscedasticity symptoms. Therefore, the CW allometry fulfilled the homoscedasticity requirement. The dispersal of residuals scattered mostly within -2 to $2 \mathrm{~m}$. The predicted values of $\mathrm{CW}$ were clustered within $2.0-5.0 \mathrm{~m}$ and distributed randomly as well. On the predicted values over $5.0 \mathrm{~m}$, the residuals were systematically overestimated.

Evaluation of the obtained CW allometry with the validation data indicated that the denoted $\mathrm{CW}$ rather overestimated with an MBE value of $0.763 \mathrm{~m}$, and the observed values scattered mostly below the predicted line (Figure 6c). In addition, the $\mathrm{CW}$ allometry was unfortunately categorized as poor with $40.8 \%$ based on the NRMSE criterion.

CW allometry for competition data set Application of the $\mathrm{CW}$ allometry for the competition data set was achieved using the following equation: $\mathrm{CWc}=1.498^{*} \mathrm{D}_{\mathrm{c}}^{0.354}$. This $\mathrm{CW}$ allometry was able to explain $\mathrm{CW}$ variations by approximately $9.1 \%$. The SSE amounted to $0.179 \mathrm{~m}$ (Figure 7a). The CW allometry, as well as all parameters, was statistically significant.

Visual investigation of the graph of residuals revealed that there was no obvious pattern (Figure 7b). This clearly indicated that there were no identified heteroscedasticity symptoms. Consequently, the $\mathrm{CW}$ allometry fulfilled the homoscedasticity requirement. The dispersion of residuals ranged primarily from -2 to $2 \mathrm{~m}$ and composed of dark cloud formation in the surrounding 0 value. On the other hand, the predicted values of CW spread in a narrow spectrum around $4.0 \mathrm{~m}$.

Evaluation of the feasibility of the obtained CW allometry with the validation data set indicated that the

Table 2 Statistics of diameter and crown width (mean \pm standard deviation; minimum-maximum); both the model fitting and the model validation are separated according to the competition status and values

\begin{tabular}{lcccc}
\hline $\begin{array}{l}\text { Data set/ } \\
\text { model } \\
\text { code }\end{array}$ & $\mathrm{N}$ & $\begin{array}{c}\text { Diameter } \\
(\mathrm{cm})\end{array}$ & $\begin{array}{c}\text { Crown width } \\
(\mathrm{m})\end{array}$ & Competition index \\
\hline Fitting & & & & \\
$\mathrm{M}$ & 4,440 & $15.7 \pm 3.6 ; 6.2-28.0$ & $3.92 \pm 0.89 ; 0.82-6.85$ & $0.00 \pm 0.64 ; 0.00-2.83$ \\
$\mathrm{M}_{\mathrm{f}}$ & 1,331 & $12.1 \pm 2.9 ; 6.2-23.0$ & $3.38 \pm 0.97 ; 0.82-5.77$ & 0.00 \\
$\mathrm{M}_{\mathrm{c}}$ & 3,109 & $17.2 \pm 2.7 ; 9.9-28.0$ & $4.15 \pm 0.75 ; 1.21-6.85$ & $0.01 \pm 0.50 ; 0.01-2.83$ \\
& & & & \\
$\mathrm{M}_{\mathrm{lc}}$ & 1,385 & $16.5 \pm 2.8 ; 9.9-25.0$ & $4.16 \pm 0.78 ; 1.21-6.53$ & $0.64 \pm 0.26 ; 0.01-1.00$ \\
$\mathrm{M}_{\mathrm{mc}}$ & 1,584 & $17.6 \pm 2.5 ; 10.8-28.0$ & $4.12 \pm 0.72 ; 1.78-6.85$ & $1.34 \pm 0.26 ; 1.01-2.00$ \\
$\mathrm{M}_{\mathrm{hc}}$ & 140 & $19.7 \pm 2.4 ; 13.1-27.0$ & $4.27 \pm 0.71 ; 2.06-5.60$ & $2.27 \pm 0.20 ; 2.01-2.83$ \\
& & & & \\
$\mathrm{Validation}$ & & & & \\
$\mathrm{M}$ & 1,080 & $18.2 \pm 3.4 ; 7.5-26.7$ & $4.23 \pm 1.04 ; 0.83-6.51$ & $0.95 \pm 0.65 ; 0.00-2.50$ \\
$\mathrm{M}_{\mathrm{f}}$ & 219 & $13.2 \pm 2.7 ; 7.5-19.1$ & $2.82 \pm 0.97 ; 0.83-5.44$ & 0.00 \\
$\mathrm{M}_{\mathrm{c}}$ & 861 & $19.4 \pm 2.2 ; 12.4-26.7$ & $4.59 \pm 0.70 ; 2.31-6.51$ & $1.19 \pm 0.49 ; 0.25-2.50$ \\
\hline
\end{tabular}




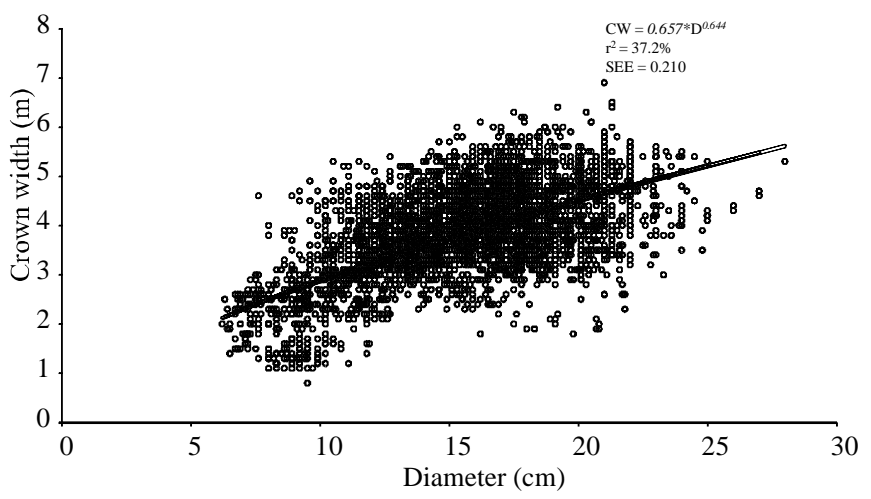

(a)

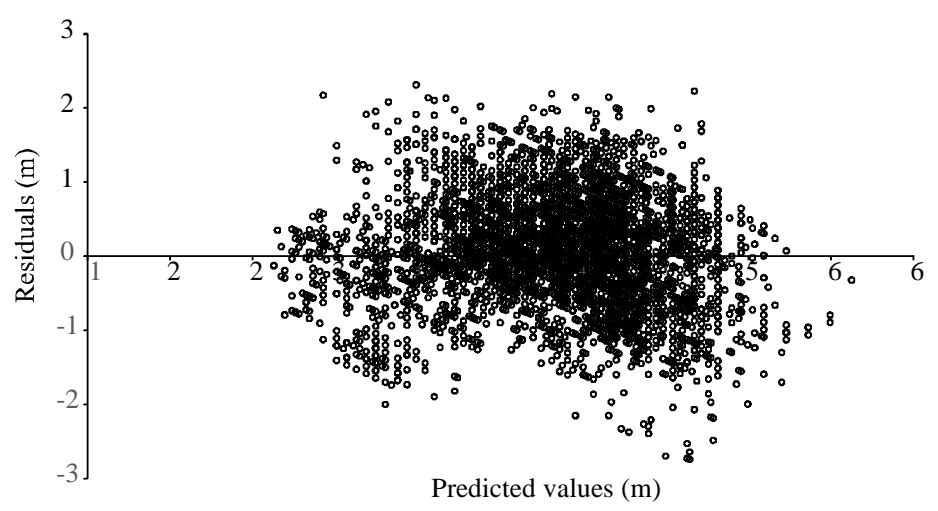

(b)

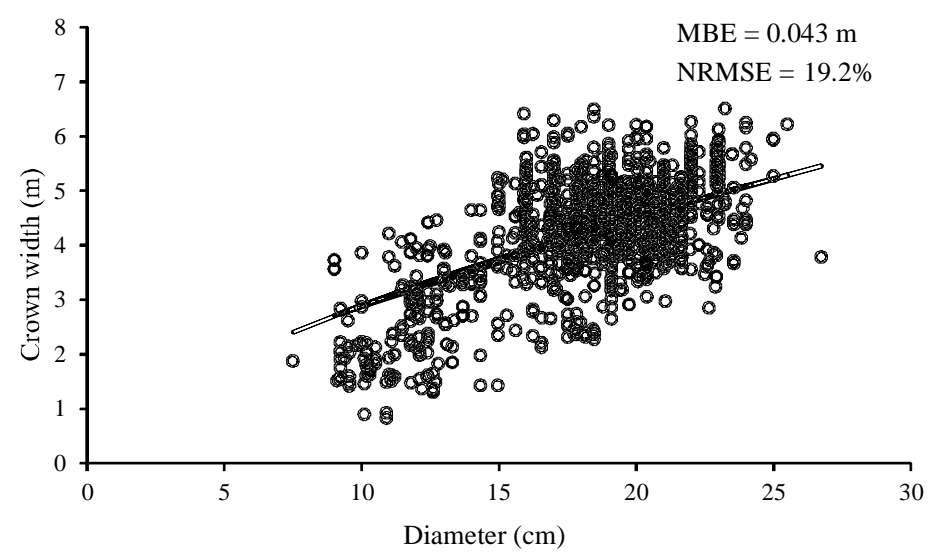

(c)

Figure 5 Evaluation of CW allometry on all data for both fitting and validation: (a) scattered plots of crown width against diameter represented with an unfilled black circle, and the obtained CW allometry is represented with a solid black line, (b) graph of residuals with predicted $\mathrm{CW}$ values indicating no obvious trend, and (c) scattered plots of observed $\mathrm{CW}$ against the obtained CW allometry over diameter.

denoted $\mathrm{CW}$ rather underestimated with an $\mathrm{MBE}$ value of $-0.314 \mathrm{~m}$, and the observed values scattered more so above the predicted line (Figure 7c). However, the CW allometry was categorized well with $16.6 \%$ based on the NRMSE criterion.

Effects of competition level on the performance of $\mathbf{C W}$ allometry The prediction accuracy, reflected by the coefficients of determination, decreased significantly with increasing levels of competition within the competition data set (Table 3). Moreover, the capability of $\mathrm{CW}$ allometry to explain the $\mathrm{CW}$ variations decreased from 14.6 to $6.4 \%$ and eventually to $0.8 \%$ for light, medium, and heavy competition levels, respectively. However, on the other hand, the SEE remained almost the same in the surrounding values of $0.17-0.18 \mathrm{~m}$. Moreover, with an increasing level of competition, the value of parameter $b_{0}$ increased initially gradually and then sharply. In contrast, the value of parameter $\mathrm{b}_{1}$ decreased initially gradually and then drastically. Both CW allometry parameters were significant for light and medium competition levels. All parameters were also significant for both $\mathrm{M}_{\mathrm{lc}}$ and $\mathrm{M}_{\mathrm{mc}}$. In contrast, the CW allometry in the heavy competition level was not significant. In addition, parameter $b_{1}$ was not significant, even though parameter $b_{0}$ was still significant. Therefore, the $\mathrm{CW}$ allometry failed to describe the $\mathrm{CW}$ variations in the heavy competition level.

The graph of CW over diameter for model fitting explained the greatest $\mathrm{CW}$ variation and displayed low prediction accuracy. Such a finding has been indicated by other relevant studies (Sharma et al., 2016 Fu et al., 2017; Sharma et al., 2017; Yuang \& Huang, 2017). Even dominant trees were taken into consideration as a proxy to accommodate the influence of site index, and CW allometry could explain only one-third of $\mathrm{CW}$ variations. Despite exhibiting a low prediction accuracy, the performance of $\mathrm{CW}$ was slightly overestimated and good in terms of feasibility. Crown widths are often overpredicted in dense stands and underpredicted in sparse stands when CW is modeled by tree size alone (Thorpe et al., 2010). Then, stand variables obviously affected the $\mathrm{CW}$ dimension (Lhotka \& 


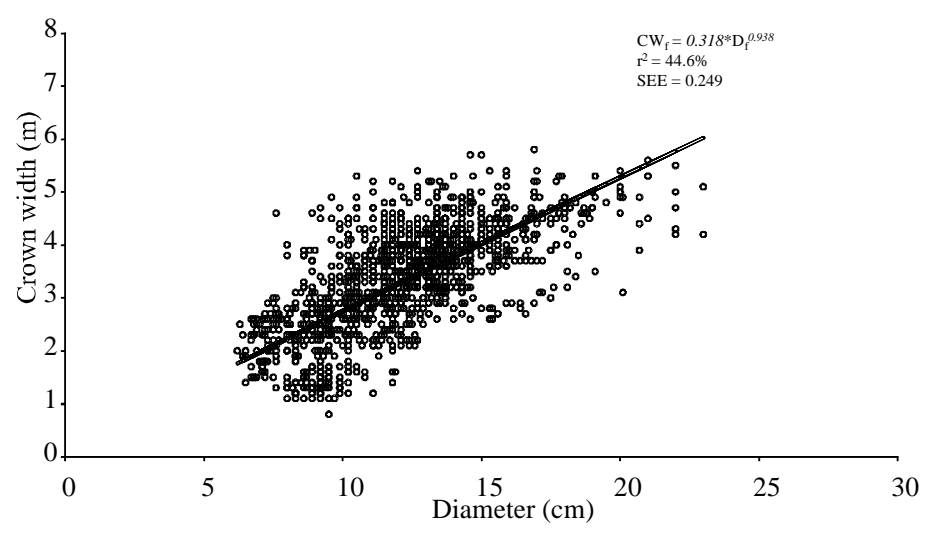

(a)

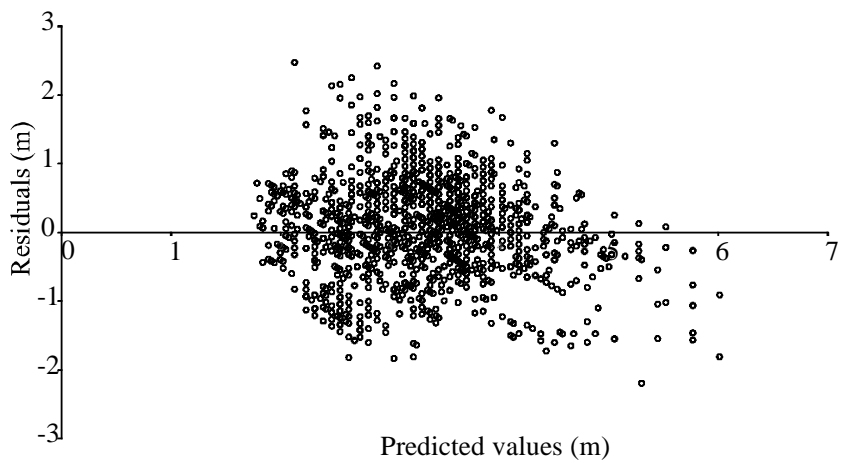

(b)

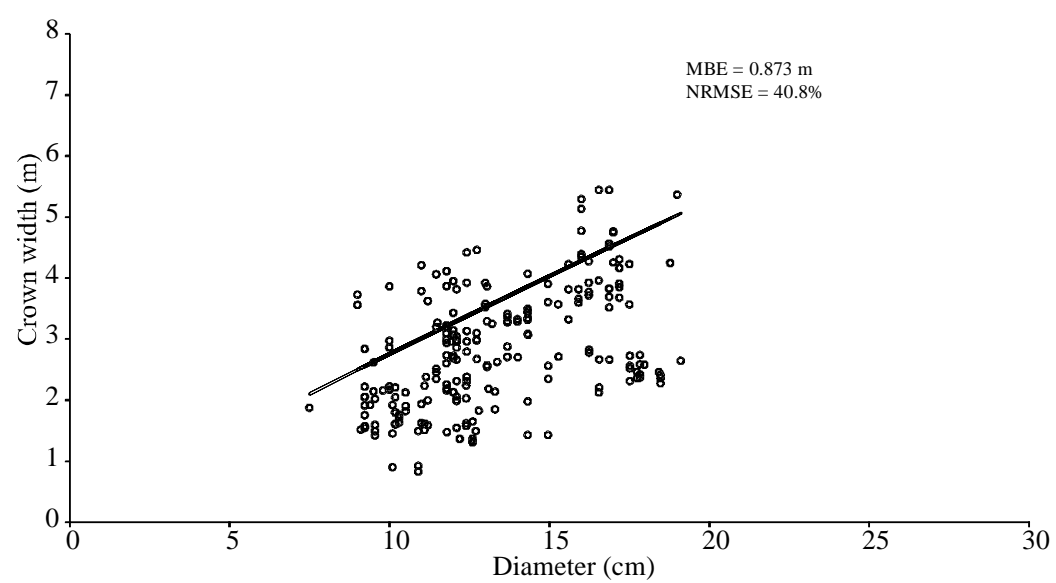

(c)

Figure 6 Evaluation of $\mathrm{CW}$ allometry on the free competition data set for both fitting and validation: (a) scattered plots of crown width against diameter are represented with unfilled black circles, and the obtained CW allometry is represented with a solid black line, (b) graph of residuals with predicted CW values indicating no obvious trend, and (c) scattered plots of observed $\mathrm{CW}$ against the obtained $\mathrm{CW}$ allometry over diameter

Loewenstein, 2011; Fu et al., 2013; Hao et al,. 2015). For this reason, a number of covariates at stand level were added to increase the percentage of $\mathrm{CW}$ variation that could be explained by the $\mathrm{CW}$ allometry (Raptis et al., 2018).

The present study then focused on the effects of competition on the quality of $\mathrm{CW}$ allometry. The comparison of $\mathrm{CW}$ allometry with and without competition data demonstrated that competition has a strong effect on the prediction accuracy. The $\mathrm{CW}$ allometry for the free competition data set revealed high prediction accuracy but was poor in terms of feasibility. In contrast, the $\mathrm{CW}$ allometry for the competition data showed lower prediction accuracy although it displayed a good level of validation. This result was quite different such that this CI has marginal contributions to crown width predictions (Yang \& Huang, 2017) and also did not significantly contribute to predict height to live crown (Yang \& Huang, 2018). On the other hand, this result was consistent with other studies showing that competition should be taken into account in the $\mathrm{CW}$ allometry (Sharma et al., 2016; Lei et al., 2018). The CW allometry was investigated in an even-aged stand, and sampled trees must compete for solar resources. Furthermore, at the tree level, CW dimensions were determined by the level of competition among trees (Yang \& Huang, 2017).

The obtained CW allometry for the free competition data set showed a similar level of prediction accuracy compared with the $\mathrm{CW}$ allometry for the privately grown plantation Neolamarckia cadamba in Malaysia (Zuhaidi, 2013). Unfortunately, this CW allometry was low in terms of feasibility. Then, the $\mathrm{CW}$ allometry rather systematically overestimated the validation data. However, on the other hand, the prediction accuracy of this $\mathrm{CW}$ allometry was lower than those of CW allometry for Anogeissus leiocarpus (DC.) Guill \& Perr and Combretum hartmannianum Schweinf in El-Nour Natural Reserve Forest, Sudan (Ibrahim \& Osman 2014). Both species were characterized by a spherical crown shape for open-grown trees where the obtained CW allometry was able to explain the variation of CW between $65 \%$ and $74 \%$.

The capability of $\mathrm{CW}$ allometry to explain $\mathrm{CW}$ variations decreased with increasing competition. The competition 

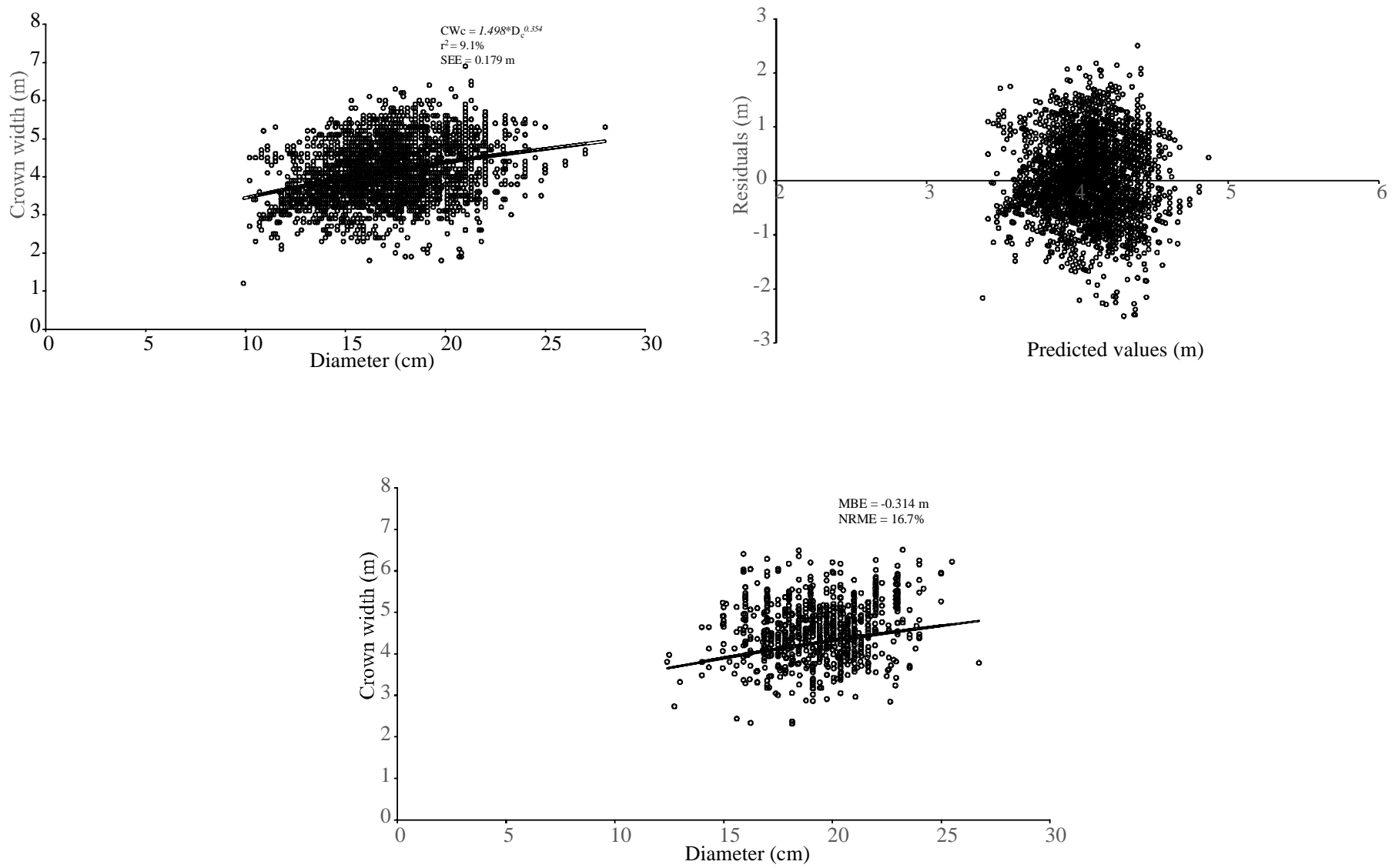

Figure 7 Evaluation of CW allometry on the competition data set for both fitting and validation: (a) scattered plots of crown width against diameter are represented with an unfilled black circle, and the obtained CW allometry is represented with a solid black line, (b) plots of residuals versus predicted $\mathrm{CW}$ values indicating no obvious trend, and (c) scattered plots of observed $\mathrm{CW}$ against the obtained $\mathrm{CW}$ allometry over diameter.

Table 3 Statistical evaluation of three CW allometry parameters within competition data, classified based on competition level

\begin{tabular}{lccccccc}
\hline $\begin{array}{l}\text { Model } \\
\text { code }\end{array}$ & $\mathrm{b}_{0}$ & $\mathrm{~b}_{1}$ & $r^{2}(\%)$ & SEE $(\mathrm{m})$ & sig.F & sig. $\mathrm{b}_{0}$ & sig. $\mathrm{b}_{1}$ \\
\hline $\mathrm{M}_{\mathrm{lc}}$ & 1.193 & 0.442 & 14.6 & 0.180 & 0.000 & 0.000 & 0.000 \\
$\mathrm{M}_{\mathrm{mc}}$ & 1.610 & 0.324 & 6.4 & 0.176 & 0.000 & 0.000 & 0.000 \\
$\mathrm{M}_{\mathrm{hc}}$ & 2.850 & 0.132 & 0.8 & 0.174 & 0.281 & 0.007 & 0.281 \\
\hline
\end{tabular}

measure was classified into three hierarchical levels, starting from light, medium, and then to heavy. The higher the values of CI increased, the lower the capability of the CW allometry explained the $\mathrm{CW}$ variations. Even, in the heavy level, the $\mathrm{CW}$ was unsuccessful in explaining the $\mathrm{CW}$ variation. These findings were consistent with a more recent study (Lei et al., 2018), indicating that competition must be taken into account in modeling the $\mathrm{CW}$.

\section{Conclusion}

We focused on the dominant trees of good-growth compartments to investigate the $\mathrm{CW}$ allometry for improved vegetative clonal teak aged more than 3 years with a $3 \times 3 \mathrm{~m}$ planting arrangement. The clonal teak is fast-growing, exhibits relatively uniform growth, and is sensitive to crown competition. Moreover, the good-growth compartments were selected as a proxy for good site quality class along with $\mathrm{CI}$ as the stand density measure. The dispersion of $\mathrm{CW}$ over diameter for all observations exhibited a clear general pattern, where the dimension of $\mathrm{CW}$ correlated positively with the size of diameter, and the obtained Pearson $r$ value was 0.58 or at a moderate level. In addition, the CI exhibited a positive correlation with both diameter and crown width, but the correlation with diameter was stronger with the Pearson $r$ 
being 0.62, rather than with crown width with the Pearson $r$ being 0.38 , even though both were at a moderate level. Competition affects the prediction accuracy of $\mathrm{CW}$ allometry. By merely involving the free competition data set, the prediction accuracy of CW allometry was better with $r^{2}=$ $44.6 \%$ than combining both free and occurred competition data sets with $r^{2}=37.2 \%$. When the merely occurred competition data set was taken into account, the prediction accuracy of CW allometry decreased drastically with $r^{2}=$ $9.1 \%$ only. Finally, investigation among the competition data sets demonstrated that the heavier the competition level, the lower the prediction accuracy of the CW allometry. Even, in the level of heavy competition, the CW allometry was completely not significant in describing the observed data.

\section{Acknowledgements}

The author would like to thank the Faculty of Forestry, Universitas Gadjah Mada, for the financial support of this study and the management of Perum Perhutani, East Java Regional Division, for an official research permit. Thanks also to the three FMUs, i.e., Madiun, Ngawi, and Saradan, for supporting fieldwork and measurement. The author is also grateful to the internal and external reviewers for their critical advice. We would like to thank Enago (enago.com) for the English language review.

\section{References}

Burkhart, E.H., \& Tomé, M. (2012). Modeling forest trees and stands. Springer, Dordrecht Heidelberg. https://doi.org/10.1007/978-90-481-3170-9

Campoe, O.C., Stape, J.L., Nouvellon, Y., Laclau, J.P., Bauerle, W.L., Binkley, D., \& le Maire, G. (2013). Stem production, light absorption and light use efficiency between dominant and non-dominant trees of Eucalyptus grandis across a productivity gradient in Brazil. Forest Ecology and Management, 288, 14-20. https://doi.org/ 10.1016/j.foreco.2012.07.035

Dahlhausen, J., Biber, P., Rötzer, T., Uhl, E., \& Pretzsch, H. (2016). Tree species and their space requirements in six urban environments worldwide. Forests, 7(6), 111. https://doi.org/10.3390/f7060111

Fayed, T.B., El-Sarag, E.I., Hassanein, M.K., \& Magdy, A. (2015). Evaluation and prediction of some wheat cultivars productivity in relation to different sowing dates under North Sinai region conditions. Annals of Agricultural Science, 60(1), 11-20.https://doi.org/10. 1016/j.aoas.2014.12.001

Fu, L., Sun, H., Sharma, R.P., Lei, Y., Zhang, H., \& Tang, S. (2013). Nonlinear mixed-effects crown width models for individual trees of Chinese Fir (Cunninghamia lanceolata) in South-Central China. Forest Ecology and Management, 302, 210-220. https://doi.org/10. 1016/j.foreco.2013.03.036

Fu, L., Sharma, R.P., Wang, G., \& Tang, S. (2017). Modelling a system of nonlinear additive crown width models applying seemingly unrelated regression for
Prince Rupprecht larch in northern China. Forest Ecology and Management, 386, 71-80. https://doi.org/ 10.1016/j.foreco.2016.11.038.

Goodman, R.C., Philips, O.L., \& Baker, T.R. (2014). The importance of crown dimensions to improve tropical tree biomass estimates. Ecological Applications, 24(4), 680-698. https://doi.org/10.1890/13-0070.1

Hao, X., Yujun, S., Xinjie, W., Jin, W., \& Yao, F. (2015). Linear mixed-effects models to describe individual tree crown width for China-Fir in Fujian province, Southeast China. PloS ONE, 10(4), e0122257. https://doi.org/10. 1371/journal.pone.0122257

Hayashi, K., Llorcaa, L., Rustini, S., Setyanto, P., \& Zaini, Z. (2018). Reducing vulnerability of rainfed agriculture through seasonal climate predictions: A case study on the rainfed rice production in Southeast Asia. Agricultural Systems, 162, 66-76. https://doi.org/10.1016/ j.agsy.2018.01.007

He, W., Yang, J.Y., Drury, C.F., Smith, W.N., Grant, B.B., He, P., Qian, B., Zhou, W., \& Hoogenboom, G. (2018). Estimating the impacts of climate change on crop yields and $\mathrm{N}_{2} \mathrm{O}$ emissions for conventional and no-tillage in Southwestern Ontario, Canada. Agricultural Systems, 159, 187-198. https://doi.org/10.1016/j.agsy.2017. 01.025

Hegyi, F. (1974). A simulation model for managing jackpine stands. In Growth models for tree and stand simulation (J. Fries, ed.). Royal College of Forestry, Stockholm, pp. 74-90.

Höwler, K., Vor, T., Seidel, D., Annighöfer, P., \& Ammer, C. (2019). Analyzing effects of intra- and interspecific competition on timber quality attributes of Fagus sylvatica L.- - from quality assessments on standing trees to sawn boards. European Journal of Forest Research, 138, 327-343. https://doi.org/10.1007/s10342-01901173-7

Huxley, J.S., \& Teissier, G. (1936). Terminology of relative growth. Nature 137, 780-781. https://doi.org/10.1038/ 137780b0

Ibrahim, E.M., \& Osman, E.H. (2014). Diameter at breast height-crown width prediction models for Anogeissus leiocarpus (DC.) Guill \& Perr and Combretum hartmannianum Schweinf. Journal of Forest Products \& Industries, 3(4), 191-197.

Lei, Y., Fu, L., Affleck, D.L.R., Nelson, A.S., Shen, C., Wang, M., Zheng, J., Ye, Q., \& Yang, G. (2018). Additivity of nonlinear tree crown width models: Aggregated and disaggregated model structures using nonlinear simultaneous equations. Forest Ecology and Management, 427, 372-382. https://doi.org/10.1016 /j.foreco.2018.06.013

Lhotka, J.M., \& Loewenstein, E.F. (2011). An individual- 
tree diameter growth model for managed uneven-aged oak-short leaf pine stands in the Ozark Highlands of Missouri, USA. Forest Ecology and Management, 261(3), 770-778. https://doi.org/10.1016/j.foreco. 2010.12.008

Li, Z.T., Yang, J.Y., Smith, W.Z., Drury, C.F., Lemke, R.L., Grant, B., He, W.T., \& Li, X.G. (2015). Simulation of long-term spring wheat yields, soil organic C, N and water dynamics using DSSAT-CSM in a semi-arid region of the Canadian prairies. Nutrient Cycling in Agroecosystems, 101, 401-419. https://doi.org/10.1007/ s10705-015-9688-3

Pachas, N.A., Sakanphet, S., Soukkhy, O., Lao, M., Savathvong, S., Newby, J.C., Souliyasack, B., Keoboualapha, B., \& Dieters, M.J (2019). Initial spacing of teak (Tectona grandis) in northern Lao PDR: Impacts on the growth of teak and companion crops. Forest Ecology and Management, 435, 77-88. https://doi.org/ 10.1016/j.foreco.2018.12.031

Pretzsch, H., Biber, P., Uhl, E., Dahlhausen, J., Rötzer, T., Caldentey, J, ..., \& Pauleit, S. (2015) Crown size and growing space requirement of common tree species in urban centres, parks, and forests. Urban Forestry \& Urban Greening, 14(3), 466-479. https://doi.org/ 10.1016/j.ufug.2015.04.006

Rahmadwiati, R., Sadono, R., Supriyatno, N. (2016) Preliminary stand table for average dominant trees of Jati Plus Perhutani in Saradan, Madiun, and Ngawi forest districs. Jurnal Manajemen Hutan Tropika, 22(1), 57-64. https://doi.org/10.7226/jtfm.22.1.57

Raptis, D., Kazana, V., Kazaklis, A., \& Stamatiou, C. (2018). A crown width-diameter model for natural even-aged black pine forest management. Forest 9, 610. https://doi. org/10.3390/f9100610

Russel, M.B., \& Weiskittel, A.R. (2011). Maximum and largest crown width equations for 15 tree species in Maine. Northern Journal of Applied Forestry, 28(2):84-91.

Sadono, R., (2014), Determining competition level for high Genetic Value of Teak (Tectona grandis L. f) aged 6 to 11 years in Madiun Forest District, East Java, Indonesia. Advances in Environmental Biology, 8(17), 750-756.
Sadono, R., Soepridjadi, D., Herningtyas, W., \& Rachmadwiati R (2016). Growing space requirement, diameter and height growth of two generative teak clones in Perhutani-the Indonesia state forest enterprise. Advances in Environmental Biology, 10(4):239-259.

Sadono, R. (2018). Prediksi Lebar Tajuk Pohon Dominan pada Pertanaman Jati Asal Kebun Benih Klon di Kesatuan Pemangkuan Hutan Ngawi, Jawa Timur. Jurnal Ilmu Kehutanan, 12(2), 127-141. https://doi.org/ 10.22146/jik.40143.

Sharma, R.P., Vacek, Z., \& Vacek, S, (2016), Individual tree crown width models for Norway spruce and European beech in Czech Republic. Forest Ecology and Management, 366, 208-220. https://doi.org/10.1016/ j.foreco.2016.01.040

Sharma, R.P., Bilek, L., Vacek, Z., \& Vacek, S. (2017). Modelling crown width-diameter relationship for Scots pine in the central Europe. Trees, 31, 1875-1889. https://doi.org/10.1007/s00468-017-1593-8

Tenzin, J., Tenzin, K., \& Hasenauer, H. (2017). Individual tree basal area increment models for broadleaved forests in Bhutan. Forestry, 90, 357-380. https://doi.org/ 10.1093/forestry/cpw065

Thorpe, H.C., Astrup, R., Trowbridge, A., \& Coates, K.D. (2010). Competition and tree crowns: A neighborhood analysis of three boreal tree species. Forest Ecology and Management, 259, 1586-1596. https://doi.org/10.1016/ j.foreco.2010.01.035

Yang, Y., \& Huang, S. (2017). Allometric modelling of crown width for white spruce by fixed- and mixed-effects models. The Forestry Chronicle, 93, 138-147. https://doi.org/10.5558/tfc2017-020

Yang, Y., \& Huang, S. (2018). Effects of competition and climate variables on modelling height to live crown for three boreal tree species in Alberta, Canada. European Journal of Forest Research, 137, 153-167. https://doi. org/10.1007/s10342-017-1095-7

Zuhaidi, Y.A. (2013). Crown diameter prediction model for plantation grown Neolamarckia Cadamba. Journal of Tropical Forest Science, 25(4), 446-453. 